\title{
Infantile hypertrophic pyloric stenosis in a six day old baby
}

\author{
U A R S Ranawaka ${ }^{1}$, A. K. Lamahewage ${ }^{2}$ \\ Sri Lanka Journal of Child Health, 2011; 40: 33
}

(Key words: infantile hypertrophic pyloric stenosis, six day old)

A six-day-old baby developed non-bilious vomiting on the second day of life while he was exclusively receiving on-demand breast-feeding. Infrequent vomiting gradually became forceful and after each breastfeed. He was active and sucking well. He was born at term after an uneventful pregnancy weighing $2.98 \mathrm{~kg}$.

On examination, he was mildly dehydrated but otherwise well. There was no palpable abdominal mass. An ultrasound scan of abdomen detected pyloric wall thickness of $4 \mathrm{~mm}$ and pyloric channel length of $17 \mathrm{~mm}$ suggesting infantile hypertrophic pyloric stenosis (Figure 1).

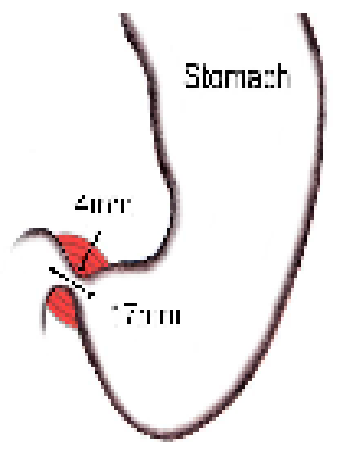

Figure 1: Pyloric wall thickness and pyloric channel length

In view of the atypical age, an upper gastrointestinal contrast study was performed and confirmed pyloric stenosis. After correction of fluid and electrolyte deficits, Ramstedt pyloromyotomy was performed. Breast-feeding was recommenced and he was sent home.

\section{Discussion}

The usual age of presentation of infantile hypertrophic pyloric stenosis (IHPS) is between 2 to 8 weeks ${ }^{1,2}$. Presentation in the first week of life is very rare. In a series of 84 patients with IHPS seen in Rajshahi from November 2000 to October 2004

${ }^{1}$ Registrar in Paediatric Surgery, ${ }^{2}$ Consultant
Paediatric Surgeon, Lady Ridgeway Hospital for
Children, Colombo

(Received on 10 November 2009. Accepted on 19 December 2009) there were no cases below 1 week of age ${ }^{2}$. A Medline literary search revealed only 2 reported instances where the age of presentation was less than one week ${ }^{3,4}$. Males have four times the risk of females ${ }^{1}$.

Ultrasound scan finding of pyloric wall thickness more than $4 \mathrm{~mm}$ and pyloric canal length of 16 $\mathrm{mm}$ confirms the diagnosis ${ }^{5}$. In our baby, due to the atypical age, despite these ultrasound scan findings, an upper gastro-intestinal contrast study was performed for further confirmation ${ }^{5,6}$.

On performing laparotomy, pyloric stenosis was confirmed. Ramstedt pyloromyotomy corrected the symptoms and he had an uneventful recovery.

\section{References}

1. Schwartz MZ. Hypertrophic pyloric stenosis. O'Neil et al editors: Paediatric Surgery. Mosby- New York 2000.

2. Jafor A, Rahman L, Choudhury KM, Hossain A. Infantile hypertrophic pyloric stenosis analysis of 84 cases. TAJ 2005; 18(1):14-6.

3. Andrassy RJ, Haff RC, Larsen GL. Infantile hypertrophic pyloric stenosis during the first week of life. Approaches to diagnosis, based on observations of a newborn whose vomiting began on the first day. Clin Pediatr (Phila) 1977; 16(5): 475-6.

4. Hatiboğlu MC, Dindar H, Cakmak M, Kanmaz T, Naycl A, Barlas M, et al. Neonatal hypertrophic pyloric stenosis: congenital or infantile? Tokai J Exp Clin Med 1996; 21(4-6):203-5.

5. Irish MS, Bovet PM et al. Hypertrophic pyloric stenosis, surgical management. emedicine, updated Sep 18, 2009. Available from:

http://emedicine.medscape.com/article/9372 63-overview

6. Godbole P, Sprigg A, et al. Ultrasound compared with clinical examination in infantile hypertrophic pyloric stenosis. Arch Dis Child 1996; 75(4):335-7. 